East African Medical Journal Vol. $79 \mathrm{No}+\mathrm{April} 2002$

SOCIO-DEMOGRAPHIC AND REPRODUCTIVE CHARACTERISTICS OF MOTHERS DELIVERED AT THE KORLE-BU TEACHING HOSPITAL. GHANA C. A. Klutio. FRCSE, FRCOG. FWACS. Associate Professor. A.T. Lassey, MRCOG. FWACS, Senior Lecturer and B. D. Annan. MRCOG. FWAC.S. Lecturer. Department of Obstetrics and Gynaecology. University of Ghana Medical School, Korle-Bu Teaching Hospital, P. O. Box 4236. Accra. Ghana.

Request for reprints to: Prof C.A. Klufio, Department of Obstetries and Gynaecology, University of Ghana Medical School, P.O. Box 4236. Accril. Glalna.

\title{
SOCIO-DEMOGRAPHIC AND REPRODUCTIVE CHARACTERISTICS OF MOTHERS DELIVERED AT THE KORLE-BU TEACHING HOSPITAL, GHANA
}

\author{
C. A. KLUFIO, A.T. LASSEY and B. D. ANNAN
}

\begin{abstract}
Objectives: To measure selected socio-demographic and reproductive history characteristics of parturients at the Korle-Bu Teaching Hospital (KBTH), Accra, Ghana, and to compute the risk load.

Design: A non-randomised cross-sectional survey.

Setting: Korle-Bu Teaching Hospital, Accra, Ghana.

Subjects: Korle-Bu Teaching Hospital, a tertiary institution delivers about 11000 women annually. From 1st November to 12th December 1994, 961 parturients were studied out of 978 delivered during the study period. Seventeen questionnaires were excluded from analysis because of errors and omissions that could not be corrected before the parturients' discharge from hospital.

Methods: The data sources were the patients' antenatal and delivery records, and a structured interviewer-administered questionnaire.

Results: More than three per cent of the subjects were less than 18 years, and $10.8 \%$ were over 35 years of age. Before the index delivery, $5.8 \%$ were grand multiparae. Eighteen per cent had never been to school. Seventeen per cent of parous subjects had experienced a perinatal death. The non-educated had significantly more births. The mean birth interval was less than two years in $26.4 \%$. Fifty percent of those who had been previously pregnant had a history of at least one induced-abortion. Only $21.0 \%$ of the 961 subjects had ever-used a family planning method. The risk load was $53.0 \%$.

Conclusion: Analysis of the historical factors of parturients surveyed at the KBTH showed a high risk load related mainly to lack of education. Formal education of the female child and family health education of our women are recommended to reduce the high past abortion rate and risk load. Additionally, postpartum tubal ligation for those who have completed their families will further reduce the risk load.
\end{abstract}

\section{INTRODUCTION}

The socio-demographic, anthropometric, reproductive and behavioural characteristics of a community have great influence on its maternal and perinatal performance (1-5). It has long been recognised that lack of formal education, low socio-economic status, high parity, short stature and low maternal weight, malnutrition, short birth intervals and pregnancies at the extremes of reproductive life lead to poor pregnancy outcomes $(1-5)$. These risk factors are common in the developing world and undoubtedly contribute in no small measure to the very high maternal and perinatal morbidity and mortality in these countries.

Periodic assessment of the prevalence of these characteristics in one's patient population is therefore useful. From August 1981 to July 1982, the Korle-Bu Teaching Hospital (KBTH) was one of 23 sub-Saharan African hospitals, which took part in a collaborative maternity care monitoring survey of postpartum women that was designed and sponsored by Family Health
International (FHI), USA. The survey studied sociodemographic characteristics, obstetric history, contraceptive practices, antenatal care, labour and delivery management, and maternal and perinatal outcomes(6).

The primary objective of the present study was to measure selected socio-demographic, reproductive, anthropometric and behavioural characteristics of our population and to compute the risk load, and secondly, to compare our findings with those of the 1981/1982 study.

\section{MATERIALS AND METHODS}

This was a non-randomised sequential survey of all mothers delivered at the KBTH from I st November 1994 to I 2 th December 1994. The KBTH delivers about 11,000 women a year. Subjects were recruited after the study had been explained to them and they had given verbal consent. No patient refused. The only other exclusion criterion was mental infirmity of a grade that made it impossible for the patient to be interviewed. The data sources were a standardised pre-tested structured questionnaire and the subjects' antenatal and delivery records. Medical students who 
were doing their senior clerkship in Obstetrics and Gynaccology were trained to administer the questionnaire. The data were collected on the patient's admission to the lying-in ward. The researchers checked each questionnaire for omissions and errors before the subject's discharge from hospital.

The labour ward register was used to identify eligible subjects. The subjects were followed to the lying-in wards and the questionnaire administered to each patient. The rest of the data were obtained from the patient's hospital records. From Ist November 1994 to 12th December 1994, 961 subjects were recruited out of 978 delivered. Seventeen questionnaires were excluded from the analysis because of errors and omissions that could not be corrected before the parturients' discharge from hospital.

Data limitations and definitions ofterms: Age of the subject was considered reliable if the patient could give both her date of birth and her age, and if the two agreed. Where the patient's given age was patently wrong, or where the patient could not give her age, the research assistant used calenclar events to make an educated guess. Parity was the number of hirths before the index delivery. A nullipara (Para 0 ) was a subject who had not had a delivery bofore this birth; a grand multipara had tive or more deliveries before the index birth. A primigravida had not had a previous pregnancy; the index pregnancy was her first. Past low birthweight: A history of past low hirth weight was accepted if the patient was able to tell the birth weight, or if she stated that the baby was small and was admitted to Neonatal Intensive Care Unit (NICU) on that account.

Perinatal death: Perinatal death is a stillbirth or death of the baby within the first week of birth.

Last birth interval: This is the number of months between the date of the penultimate delivery and the date of the index birth. Height was as measured and recorded during the antenatal period.

Family planning experience: If the subject had used more than one method, the most effective method was selected. The enquiry did not examine duration or regularity of use, or discontimuation rates and reasons for discontinuation. Gestational age was taken as reliably established if the palient was sure of her dates and at the booking visit. the fundal height was equal to the date, or, if the patient had an ultrasound scan dating before the sixill week

Antenttal weight: Weight gain wats obtained by subtracting the first recorded weight from the last. To reduce the modifying effect of preterm delivery and late booking, only subjects whose first weights were taken not later than 26 weeks and whose last weights were after 36 weeks were included in the analysis.

Historical risk load: The historical risk load was the percentage of subjects with a historical risk factor in the total sample. The percentage was determined in a series of steps. First, a list of the risk factors was made. Next, the number of subjects in the total sample with each risk factor was counted. At the third step, the factor with the highest lrequency of subjects was deleted from the total sample. At the lourth step, the factor with the next highest frequency was removed from the residual sample; and so on, in descending order to the end of the list, or until a subsequent step produced a count of zero risk factors. A subject with multiple factors was therefore counted only once. The total number of subjects with a risk lactor was then expressed as a percentage of the total sample. The historical risk factors examined, included no schooling, birth interval less than two years, unmarried status, age less than 18 years, age more than 35 years, past perinatal death, no antenatal care, a past low birth weight infant and grand multiparity. Previous primary postpartum hacmorrhage was excluded because recall bias made the information unreliable except in the very severe cases.

Lost antenatal records, measurements not recorded in the hospital notes and "don't know" answers to items in the questionnaire were treated as missing values in the analysis.

\section{RESULTS}

Socio-demographic characteristics: ethnic origin of parents of subjects: Father: As was to be expected with KBTH being in the Grealer Accra Region, this region contributed the largest proportion (28.3\%), followed by the Eastern $(18.4 \%)$, Volta $(15.3 \%)$, Central (11.3\%), Ashanti (8.1\%), Northern (4.3\%), and Upper Regions (4.0\%). Brong Ahafo and Western Regions contributed just over $1 \%$ each, and $7.8 \%$ were non-Ghanaian.

Mother: The figures were strikingly similar to those for the lathers. Excluding those with non-Ghanaian parentage, in $20 \%$ of the cases both parents were from different regions.

Age: The age was reliable in 592 subjects, and only these patients were used for this analysis. The mean age was $27 \pm 6.1$ years with a range of 15-53years. and a median of 27 years. The 10 th and 90 th percentiles were 20 years and 36 years, respectively. Twenty one $(3.5 \%)$ subjects were less than 18 years and $64(10.8 \%)$ were more than 35 years old. Two hundred and seventy five subjects had no previous deliveries. For this nulliparous subgroup, the mean age was $23 \pm 4.6$ years, the range $15-37$ years, and the median 23 years. The 10 th and 90 th percentiles were 18 years and 30 years, respectively. Twenty of the $275(7.3 \%)$ subjects were less than 18 years and three (1.1\%) were more than 35 years old.

Residential area: Fifty seven per cent of the subjects lived in urban slums. Only $2.9 \%$ lived in villages.

Religion: Christians formed the greatest majority (83.8\%). Moslems constituted $10.7 \%$; whilst $4.0 \%$ did not profess to any religion, and $1.5 \%$ followed a traditional or another religion.

Marital status: One in ten of the subjects were not currently marricd.

Education: The mean number of years of schooling was $7.9 \pm 4.97$ years. The median was 9.0 years. One hundred and seventy-five (18.2\%) had never been to school, whilst $240(25 \%)$ had completed more than 10 years.

Past obstetric history (Table 1): Parity ranged from 0 to eight deliveries per subject; the mean was $1.3 \pm 1.66$ past births. Nulliparae formed $43.2 \%$, and the grand multiparae formed $5.8 \%$ of the total sample. The parity characteristics are summarised in Table 1 . The mean number of years of schooling ( $4.2 \pm 4.81$ years) of the grand multiparae was significantly less than the mean $(8.0 \pm 5.02$ years $)$ for the para $1-4$, and the $8.3 \pm 4.72$ years for the nulliparae $(p<0.001)$. Significantly more of the para 5 had never been to school $(51.8 \%$ versus $16.1 \%, p<0.001$, odds ratio $=5.58$ and $95 \%$ confidence interval of odds ratio=3.09-10.11). 
Table 1

Parity and past preghamcy outcomes

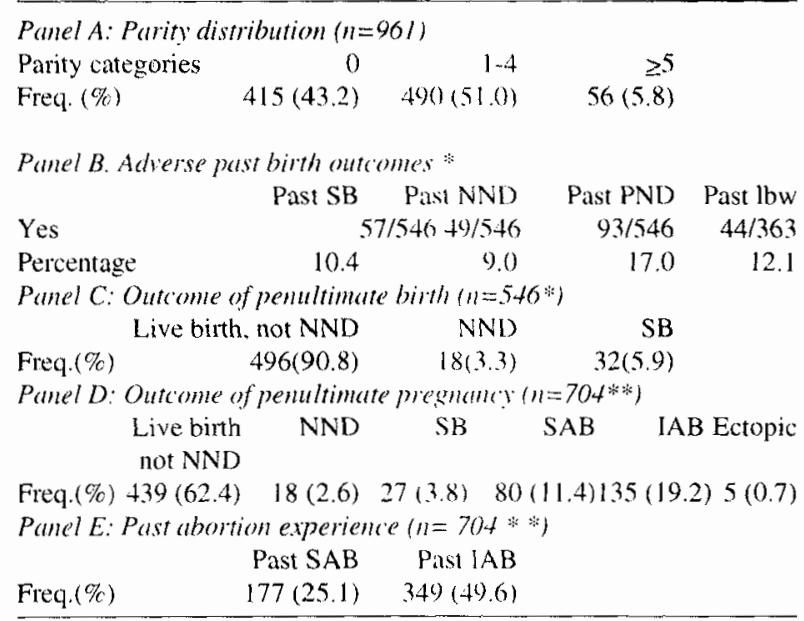

"Nulliparae excluded: **Primigravidac excluded: $\mathrm{NND}=$ neonatal death: $S B=$ stillbitth; PND = perinatal death; $l$ bw = low birth weight; $\mathrm{SAB}=$ spontaneous abortion; $\mathrm{IAB}=$ induced abortion

Past perinatal death: Of the 546 parous subjects with previous deliveries, $57(10.4 \%)$ had a previous history of stillbirth, $49(9.0 \%)$ had a previous early neonatal death, and $93(17.0 \%)$ had a previous history of at least one perinatal death (a stillbirth or an early neonatal death). Three hundred and sixty three parous patients could answer the question about past low birthweight. Forty four (12.1\%) of the 363 had delivered a low birth weight infant in the past. Fifty $(9.2 \%)$ of the 546 penultimate births produced a perinatal death ( 18 neonatal deaths and 32 stillbirths).

Outcome of last pregnancy: Of the 704 subjects for whom this index pregnancy was not the first, the outcome of the last pregnancy was as follows: live birth 439 $(62.4 \%)$, neonatal death $18(2.6 \%)$, stillbirth 27 (3.8\%), spontaneous abortion $80(11.4 \%)$, and an induced abortion $135(19.2 \%)$.

Past abortions: Of the 704 subjects who had at least one previous pregnancy, $177(25.1 \%)$ had a previous history of spontaneous abortion and $349(49.6 \%)$ had one or more induced-abortions. Schooling had a positive association with induced-abortion. The mean number of years of schooling for the subjects with a history of induced-abortion was $8.9 \pm 5.36$ years, compared with $7.2 \pm 5.40$ years for those with no such history. The difference was significant $(p<0.001)$. Among those with a history of induced-abortion, the proportion that had ever been to school was $90.0 \%$ compared with $74.1 \%$ of those without a history of inducedabortion. The difference was significant $(p<0.01$, odds ratio $=3.14$ and $95 \%$ confidence interval of odds ratio $=2.02$ 4.90). On the other hand, parity was negatively associated with past induced-abortion. The proportion of subjects with a history of induced-abortion decreased with increasing parity: $82.3 \%$ of para $0,41.2 \%$ of para $1-4$, and $30.4 \%$ of para $5 \quad(\mathrm{p}<0.001)$.

Last birth interval: The mean interval between the last birth and this birth was $55.3 \pm 34.60$ months; the range was $11.0-240.0$ months and the median 48.0 months. The 10 th and 90 th percentiles were 24.0 and 108.0 months, respectively. The interval was less than 24 months in 26.4\% (144/546).

Family planning experience: Twenty one per cent of the subjects had ever used a family planning method; and only $22.6 \%$ of those who had ever been pregnant used a method in the interval between the end of the last pregnancy and the beginning of this pregnancy.

Antenatal care in index pregnancy: Ninety four per cent $(903 / 961)$ attended for antenatal care in the index pregnancy (Table 2, Panel A). Of the 961 subjects, 58 $(5.6 \%)$ attended a facility only once, whilst $698(80.9 \%)$ attended three or more times. The ge tational age was reliable in 486 subjects (Table 2, Panel B). For this subgroup, the mean gestation at the first antenatal visit was $22.2 \pm 6.59$ weeks. The 10 th and 90 th percentiles were 14.0 and 31.0 weeks, respectively. Forty subjects $(8.2 \%)$ booked in the first trimester, $343(70.6 \%)$ in the second trimester, and $103(21.2 \%)$ booked in the third trimester. At least one ultrasound scan examination was performed in $492(51.2 \%$ ) of the 961 subjects (Table 2, Panel C). Twenty ultrasound scan reports could not be traced

Table 2

Antenatal clinic visits and first ultrasond scan examination

Panel A: No. of antenatal visits $(n=961)$

$\begin{array}{llllll}\text { No. visits } & 0 & 1 & 2 & 3 & 4\end{array}$ Freq. (\%) $\quad 58(6.0) \quad 54(5.6) \quad 72(7.5) \quad 79(8.2) \quad 698(72.6)$

Panel B: Gestational age of booking visit $(n=486 *)$

Gestation (weeks) $13 \quad 14-26 \quad 27-41$

Freq. $(\%) \quad 40(8.2) \quad 343(70.6) \quad 103(21.2)$

Panel C: Gestational age (GA) of first ultrasound scam (n=472**)

GA of first scan $13 \quad 14-26 \quad 27-41$

Freq.(\%) $\quad 26(5.5) \quad 170(36.0) \quad 276(58.5)$

*Unreliable dates excluded. **Number of missing scan reports $=20$

For the remaining 472 , the first scan was done in the first trimester in $5.5 \%$, in the second trimester in $36.0 \%$, and in the third trimester in $58.5 \%$.

Type of antenatal facility attended: The antenatal clinics attended by the 903 subjects who attended a clinic are listed in Table 3. Five hundred and sixty six (62.7\%) subjects attended the KBTH antenatal clinic; $452(50.1 \%)$ attended only this clinic, and $114(12.6 \%)$ attended the KBTH antenatal clinic and another clinic. Compared with those 18 years or older, significantly more of the less than 18 year olds did not attend for antenatal care ( $19.0 \%$ versus $3.9 \%, p<0.01$, odds ratio $=5.87$ and $95 \%$ confidence limits of odds ratio $=1.32-20.06$ ). Amongst the never been to school, the proportion who had no antenatal care was significantly higher than the proportion among those who had been to school (14.9\% versus $4.1 \%, p<0.001$, odds ratio $=4.11$ and $95 \%$ confidence limits of odds ratio $=2.29-7.38$ ).

Anthropometric characteristics (Table 4): Maternal 
height ranged from $130-180 \mathrm{~cm}$; the mean was $159.5 \pm$ $6.74 \mathrm{~cm}$, the median $160 \mathrm{~cm}$, and the $10 \mathrm{th}$ and $90 \mathrm{th}$ percentiles were 150.0 and $168.6 \mathrm{~cm}$, respectively. The proportion below $150 \mathrm{~cm}$ was $3.6 \%$.

\section{Table 3}

Type of antenatal farility attended

\begin{tabular}{lr}
\hline Name/Type of facility & Freq (\%) N=903 \\
\hline Korle-Bu Teaching Hospital (KBTH) & $452(50.1)$ \\
Urban Polyclinic (UP) & $220(24.4)$ \\
UP + KBTH* & $86(9.5)$ \\
Private midwife & $69(7.6)$ \\
Other Govt. Hospital & $27(3.0)$ \\
General Practitioner (GP) & $21(2.3)$ \\
Midwife + KBTH* & $19(2.1)$ \\
GP + KBTH* & $9(1.0)$ \\
\hline
\end{tabular}

* Shared care

Table 4

Maternal anthropometric characteristac

Panel A: Maternal height com $(n=89.3\}$

Mean $\pm \mathrm{SD} \quad$ Median 10 th Pc goth Pe Range

$\begin{array}{lllll}159.5 \pm 6.74 & 160 & 150.0 & 168.6 & 130 \% 180\end{array}$

Panel B: Maternal height categories $(11=8 \% 3)$

$\begin{array}{llll}\text { Height (cm) categ 130-149 } & 150-159 & 160-169 & 170\end{array}$

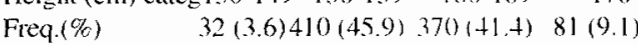

Panel C: Matemal weigh $\mathrm{kg}(n=2 / 0:)$

$$
\text { Mean+SD Median loth Pc 90th Pc Range }
$$

Booking

$\begin{array}{llllll}\text { weight: } & 67.3+13.82 & 64.5 & 51.6 & 86.0 & 43.5-114.5\end{array}$ Last weight $73.7+13.89 \quad 71.0 \quad 57.5 \quad 92.0 \quad 49.0-118.0$

*Booking weight gestation $>26 \mathrm{wks}$ and last weight $<37 \mathrm{wks}$ excluded. $\mathrm{PC}=$ percentile

Maternal weight: By the criteria enunciated under 'data limitations', 210 subjects were eligible for analysis. First antenatal weight ranged from 43.5 to $114.0 \mathrm{~kg}$; the mean was $67.3 \pm 13.82 \mathrm{~kg}$, the median $64.5 \mathrm{~kg}$, and the $10 \mathrm{th}$ and 90 th percentiles 51.6 and $86.0 \mathrm{~kg}$, respectively. The last antenatal weight ranged from 49.0 to $118.0 \mathrm{~kg}$; the mean was $73.7 \pm 13.89 \mathrm{~kg}$, and the median was $71.0 \mathrm{~kg}$. The mean antenatal weight gain was $6.5 \pm 3.94 \mathrm{~kg}$. Of the 961 subjects, $509(53.0 \%)$ had at least one historical risk characteristic.

\section{DISCUSSION}

Studies from all over the world have shown that maternal and infant mortality rates are highest in women with the following characteristics: age $<18$ years, age $>35$ years, grandmultipara (Para $\geq 5$ ), and pregnancies spaced $<24$ months apart. These four are additive in their effect so that a combination of two or three has increasingly greater influence(1-3). Fourteen per cent (one in seven) of our subjects were in the "high risk" age groups.
In the developing world, antenatal care has a pivotal role in strategies aimed at reducing maternal and perinatal mortality. The beneficial effect of antenatal care on perinatal outcome is independent of mother's education(8). In the $1981 / 82$ study, $6.7 \%$ of the subjects did not visit a clinic; this is not very different from the six per cent we found. The workers in the 1981/82 study concluded: "whether or not a woman receives antenatal care, and when in her pregnancy the care is initiated, were associated with the outcome of the pregnancy". It also reported that, "... within each parity group, infants of mothers with no prenatal visits were less likely to survive until the mothers' discharge from the hospital than infants of women who had some visits"(8). Nearly $20 \%$ of our subjects either did not attend a clinic or visited only once or twice. If we say that for any useful care to be given, a minimum of three visits is necessary, then nearly one in five of our subjects did not have antenatal care. In general adolescents do not attend for antenatal care, or, are late and irregular antenatal clinic attendees (3,9-11). This risk behaviour was confirmed in this study. Adolescent pregnancy and childbirth are associated with higher morbidity and mortality rates than are found in women who are 20-29 years old, especially in the absence of adequate medical care. Maternal mortality rates in girls under 18 years are two to five times the rates in older women(12). The common causes of maternal death in these girls are prolonged and obstructed labour from cephalo-pelvic disproportion, haemorrhage, unsafe abortion, pregnancy-induced hypertension, severe malaria and anaemia(8,12-14). Grand-multiparity is associated with anaemia and the maternal depletion syndrome, malpresentation and obstructed labour, ruptured uterus. retained placenta and primary post-partum haemorrhage(15).

Almost one out of five of the subjects had never been to school. Women with education are more likely to marry and have babies at later ages and to use family planning methods (16). They are more likely to: have fewer children, make use of available obstetric services, lead a healthy life-style, avoid customary practices which may have adverse effects on pregnancy outcome, and give their children better care. Education of women, therefore, improves family health and makes childbearing safer(3$5,15,16)$. In this study, the proportion of the never been to school that did not have antenatal care was larger than the proportion of the ever been to school that did not have antenatal care.

The mean parity of our total sample was $1.3 \pm 1.66$ compared with 1.9 in 1981/82(17). In 1981/1982, the birth interval was 37.5 months(18). In this study, it was $57.2 \pm$ 34.59 months. In $1981 / 1982$, just over $20 \%$ of the subjects reported a past induced-abortion( 19); the figure was $49.6 \%$ in this study. The marked increase may be due to underreporting in the previous study. On the other hand, if the increase is real, then greater accessibility to abortion services, provided by a proliferation of elinics since then, may explain it. Many of these clinics do not offer post- 
abortion contraceptive counselling and services.

The mean height of our total sample was $159.5 \pm$ $6.74 \mathrm{~cm}$. This is close to the $160.4 \pm 6.8 \mathrm{~cm}$ for 538 primigravidae studied in this institution in 1993(20).

It was disappointing to find that only $21 \%$ of the subjects had ever used a family planning method and only $22.6 \%$ of parous subjects had used a method in the last pregnancy interval. Although, compared with 1981/1982, there has been some improvement in the characteristics of our population, for example, lower mean parity and longer birth intervals, the risk load of $53.0 \%$ is unacceptably high.

Accurate estimation of gestational age is essential for optimum obstetric management. This requires the patient to know her last menstrual period and to book early, that is, to report at the clinic at less than 20 weeks' gestation, to allow validation of the gestational age. In our sample, gestational age could not be reliably established in $47.5 \%$. If this had been included in the model, the risk load would have been even larger.

Measures which can be taken immediately to reduce the risk load include: formal education for girls; sex and health education, stressing the dangers of induced-abortion, grand multiparity, short birth intervals and births at the extremes of the reproductive age and lastly, the promotion of cheap and accessible family planning methods. An energetic programme of antenatal care and counselling and postpartum mini-laparatomy tubal ligation for those who have completed their lamilies is also recommended. The sex and health education should reach all; the neverbeen-to-school and school-dropouts must be especially targeted, using methods and language, which they can understand.

\section{REFERENCFS}

1. Rinehart W., Kols A. and Moore S.H. Healthier mothers and children through family planning. Population Reports Series J. No. 27 Baltimore, The Johns Hopkins University, Population Information Program May-June 1984 pp J657-1696

2. LeGrand T.K. and Mbacke C.S.M. Tcenage pregnancy and child health in the urban Sahel. Stud. Fitm. Plann. 1993: 24: 1.37-149.

3. Liskin L., Kak N., Rutledge A.H., Smit L.C. and Stewart L. Youth in the 1980s: Social and Health Concerns. Population Reports Series M. No. 9. Baltimore, Johns Hopkins University, Population information Program Nov-Dec 1085. pp M349-388.

4. Harrison K.A. Approaches to reducing maternal and perinatal mortality in Africa. In: Philpot R.H., ed. Maternity services in the developing world - what the community needs. London, Royal College of Obstetricians and Gynaccologists, 1980; pp52-95.
5. London K., Cushing J., Cleland J., Andersons J.E.. Morris I.. Moore S.H. and Rutstein S.O. Fertility and family plamning surveys: an update. Population Reports, Series M, No. 8. Baltimore, Johns Hopkins University. Population Information Program, Sep-Oct 1985, p60.

6. Reproductive Health In Africa: Issues and options. Janowitz B. Lewis Jo Ann, Burton N., Lampley P. eds. Research Triangle Park. NC. USA: Family Health International 1984. pp 64

7. Lassey A.T. Klufio C.A.. Annan B.D. and Wilson J.B. Antenatal haemoglobin profile at Korle-Bu Teaching Hospital. Ecist Afr Med J. 1999: 76:228-2.32.

8. Smith J. Jenowitz B. Maternal Care: Antenatal Care, In: Janowits B., Lewis J., Burton N., Lamptcy P., eds. Reproductive Health in Africa: Issues and Options. Research Triangle Park. NC. Family Health International 1984: 2:13-16.

9. Zabin L.S. and Kiragu K. The health conser uences of adolescent sexual and fertility behaviour in sub-Sahar. n Africa. Stud. Fom. Plann. 1998:29:210-2.32.

10. Fortney J.A. and Janowitz B.S. Does teenage pregnancy jeopardse later biths? Advances in Planned Parenthod 1970): 14:52-60.

11. Singh S. Torres A and Forrest J.I). The need for prenatal care in the United Siates: evidence from the 1980) National Fertility Survey. Fam. Plamm. Perspert. 1985: 17:118-124

12. Kilbourne-Brook M., MeKay P. and Swan D. Adolescent reproductive health: Making a difference. Orflook 1098; 16:1-8.

13. Harrison K.A., Rossiter C.E., Chong H., Lisicr U.G., Bano Q. Briggs D., Ekwempu C.C. and Member M.T The influence of maternal age and parity on childbearing with special reference to primigravidae aged 15 and under. J. Obstet. Ginter. 1985 , 92:23-31

14. Family Health Intemational (FHI) NC, USA. Adoleseents and Fentitity. Network, Fall 1988:101:2.

15. Letmmaier C. Liskin L.. Church C.A., Harris J. Mothers Lives Matter: Maternal Health in the Community. Population Reports Series L. No. 7. Baltimore. The Johns Hopkins University, Population Information Progran Sept 1988; ppl-32

16. The Alan Gutmacher Institute (AGD). Issues in Brief: Risks and Realities of early childhearing Worldwide. Now York: ACil February 1997

17 Nichols D. Birth Spacing: Family sizc. Infant Mortaluty and Desire for Additional Children. In: Janowitz B., Lewi J.. Burton N., Lamptey P., eds. Reproductive Health in Africa: Issues and Options. Research Triangle Park. NC. Family Healm Intenational 1984 : 3.35-39.

18. Janowitz B. and Smith J. Birth Spacing: Pregnancy Intervals, Breastfeeding and Contraception. In: Janowit B. Lewis J., Burton N., Lamptey P., eds. Reproductive Health in Africi: Issues and Options. Research Trangle Park, NC. Family Healh International 1984: 3:40-47

19. Smith J and Janowitz B. Birth Spacing: Pregnancy Wastage, In: Janowitz B., Lewis J., Burton N., Larnpley P., eds. Reproductive Health in Africa: Issues and Options. Research Triangle Park, NC Family Health Internationat 1984; 3:48-51

20. Kwawukume E.Y., Ghosh T.S. and Wilson I B. Maternal height as a predictor of vaginal delivery. Int. J. Gyner Obstet. 1993;41 $27-30$. 